\title{
Effects of Nanoparticles on Rheological Behavior of Polyacrylamide Related to Enhance Oil Recovery
}

\author{
Mohd Bilal Khan*, Mohd Faizan Khoker, Mustafiz Husain, Moughes Ahmed and Shams Anwer \\ Department of Petroleum Studies, Aligarh Muslim University, India
}

Submission: July 13, 2018; Published: October 03, 2018

*Corresponding author: Mohd Bilal Khan, Department of Petroleum Studies, Aligarh Muslim University, Aligarh-202002, India,

Email: bilalkh009@gmail.com

\begin{abstract}
The effect of nanoparticles $\mathrm{SiO}_{2}, \mathrm{TiO}_{2}$ and $\mathrm{Fe}_{2} \mathrm{O}_{3}$ on the rheological behavior of anionic polyacrylamide and a mixed assembly of polymer and cationic surfactants were measured systematically by shear viscosity and oscillatory testing at different concentration of Nano-materials. The results of shear viscosity measurement indicate that for all of the systems, the shear viscosity increases with the addition of nanoparticles and show shear thinning behavior at low shear rate. In the oscillatory test, all of the systems show elastic behavior, which depend on the concentration of nanoparticles. The storage modulus $\left(G^{\prime}\right)$ and loss modulus ( $\left.G^{\prime \prime}\right)$ increased as nanoparticles concentration increase. The core flooding experiment were also done with polymer-surfactant solution in presence and absence of nanoparticles and the obtained result indicates the higher oil recovery in presence of nanomaterials. In enhance oil recovery process; the viscosity and viscoelasticity are key parameters for the success of the recovery process.
\end{abstract}

Keywords: Wettability; Viscoelasticity; Displacement efficiency; Nanoparticles

\section{Introduction}

Due to the increasing demand of energy and diminishing amount of conventional oil, the oil industries have been relying on enhanced oil recovery methods for decades. Presently, lots of researches are being carried out globally to improve enhanced oil recovery techniques to fulfill the demands of oil. Recently, the use of nanoparticles in enhance oil recovery has been proved very efficient. With a nano size and large surface area to volume ratio, nanoparticles have the potential to penetrate the pores in the reservoir rocks where conventional enhance oil recovery process are unable to. The nanoparticles can alter the oil reservoir characteristics such as mobility ratio, wettability, interfacial tension, injected fluid viscosity and are stable than the polymersurfactant at harsh and saline conditions [1-3]. The oil recovery decreases by increasing the salt concentration during the polymer flooding, whereas in the case of flooding with a suspension of nano-silica in the polymer, decreasing the rate of oil recovery is lower [4]. The nanoparticles are more capable of the reduction of interfacial tension and the alteration of wettability in the case of light oil reservoir [5].

In the last decade, nanoparticles have attracted many researcher's attention in the field of enhance oil recovery due to their unique properties. Maghzi et al., [6] reported that at the same salinity, the oil recovery is $10 \%$ higher with nanoparticles than the polymer flooding in the absence of nanoparticles. Hu et al., [7] reported that with $5 \mathrm{ppm}$ concentration of nanoparticles recovered the original oil in place about $35.8 \%$, with $10 \mathrm{ppm}$ of nanoparticles it is $41.8 \%$ and with $20 \mathrm{ppm}$ of nanoparticles, $39.8 \%$ of original oil in place was recovered. At low nanoparticles concentrations, the rate of recovery of oil increases with an increase of nanoparticles concentration and reaching a peak value at $20 \mathrm{ppm}$, above which it starts to decline.

Joonaki et al., [8] reported in his result, the total oil recovery by using nanoparticles is $92.5 \%, 88.6 \%$ and $95.3 \%$ in the three scenarios. This result indicates that the oil recovery will be higher, and less amount of oil is remaining trapped within the porous media, if the nano fluid injection begins earlier. In the experiment of Pei et al., [9], 50\% of the OOIP were recovered with silica nanoparticles. These results demonstrate that the injection of nanoparticles with polymer and surfactant system can significantly increase the wettability, reduce the mobility ratio and thus leads to the improvement of enhance oil recovery. Yousefvand et al., [10] reported in his paper that the oil recovery factor after one pore volume of the injected fluid has been obtained and results indicate that in the presence of nano silica an improvement about $10 \%$ in the ultimate oil recovery can be achieved and this is due to the viscosity enhancement of the injected fluid. Also, nanoparticles have ability to change the wettability to water-wet in some portions of the micro model.

In this study, we have organized a series of experiments to know the potential effects of nano-materials on the rheological behavior of polyacrylamide solution. The sample viscosities 
in different concentrations of nanoparticles, shear rates, temperature were measured. Because the viscosity plays a very important role in enhance oil recovery. Also, this paper presents a comparison between the effects of different nanoparticles on the rheology of polyacrylamide in the presence of surfactants. In addition, the viscoelasticity of polyacrylamide solution in the presence of different nanoparticles was also measured.

\section{Procedure}

\section{Materials}

For this study, polyacrylamide (PAM) of molecular weight 150000, was purchased from Sigma Aldrich, U.S.A. CTAB surfactant ( $\geq 99.0 \%$, Merck, Germany) was used as received. Gemini surfactants $\alpha, \omega$ - bis (hexadecyldimethylammonium) alkane dibromides (16-6-16 and 16-5-16) were prepared and purified. Also, three types of nanoparticles were used for this study. These nanoparticles are Silica fumes (particle size $0.007 \mu \mathrm{m}$, specific surface area $395 \pm 25 \mathrm{~m}^{2} / \mathrm{g}$, density $36.8424649 \mathrm{~kg} / \mathrm{m}^{3}$ ), $\mathrm{TiO}_{2}$ (particle size $<100 \mathrm{~nm}$, purity $99.5 \%$ trace metal basis, specific surface area $50-100 \mathrm{~nm}$ ) and $\mathrm{Fe}_{2} \mathrm{O}_{3}$ (particle size 50$100 \mathrm{~nm}$, purity $97 \%$ trace metal basis, specific surface area 40 $60 \mathrm{~m}^{2} / \mathrm{g}$ ) was purchased from Sigma Aldrich, St. Lucia, U.S.A. All the experiments were conducted at $50{ }^{\circ} \mathrm{C}$ and all the solution was prepared in double distilled water (Table 1).

Table 1: Name, Molecular weight, formulas and purity of material used.

\begin{tabular}{|c|c|c|c|c|}
\hline Name & Molecular wt. & Formula & Make & $\%$ Purity \\
\hline \multicolumn{5}{|l|}{ Polymer used } \\
\hline Polyacrylamide & 15,000 & $\left(\mathrm{C}_{3} \mathrm{H}_{5} \mathrm{NO}\right)_{\mathrm{n}}$ & Sigma-Aldrich, USA & $99.00 \%$ \\
\hline \multicolumn{5}{|l|}{ Surfactants used } \\
\hline Cetyltrimethyl Ammonium bromide & 364.8 & $\mathrm{C}_{19} \mathrm{H}_{42} \mathrm{BrN}$ & Merck, Germany & $99.0 \%$ \\
\hline Gemini 5 & 768.22 & $\mathrm{C}_{41} \mathrm{H}_{88} \mathrm{~N}_{2} \cdot 2 \mathrm{Br}-$ & Self-synthesized & $98.50 \%$ \\
\hline Gemini 6 & 782.22 & $\mathrm{C} 42 \mathrm{H} 90 \mathrm{~N} 2.2 \mathrm{Br}-$ & Self-synthesized & $98.50 \%$ \\
\hline \multicolumn{5}{|l|}{ Nanoparticles } \\
\hline Nano-silica oxide & & $\mathrm{SiO}_{2}$ & Sigma-Aldrich, USA & $99.00 \%$ \\
\hline Nano-titanium oxide & & $\mathrm{TiO}_{2}$ & Sigma-Aldrich, USA & $99.50 \%$ \\
\hline Nano-iron oxide & & $\mathrm{Fe} 2 \mathrm{O}_{3}$ & Sigma-Aldrich, USA & $97.00 \%$ \\
\hline
\end{tabular}

\section{Preparation of solution}

The polymer solution of $1.0 \mathrm{wt} \%$ concentration was prepared in distilled water. The nanoparticle of $\mathrm{SiO}_{2}, \mathrm{TiO}_{2}$, $\mathrm{Fe}_{2} \mathrm{O}_{3}$ in a concentration of $0.2 \mathrm{wt} \%$ to $1.0 \mathrm{wt} \%$ was mixed with polyacrylamide solution. After conducting several tests of polymer and nanoparticle mixture, we add cationic surfactants with these solutions. It is also observed that above $1.0 \mathrm{wt} \%$ of a nanoparticle of $\mathrm{SiO}_{2}$ and $\mathrm{TiO}_{2}$ (except $\mathrm{Fe}_{2} \mathrm{O}_{3}$ ), the solution of polymer and Gemini surfactants gets precipitated. This will set the limit and we add the nanoparticle at low concentration very carefully. The solutions of polymer-surfactant-nanoparticle are not easily mixed with each other and the solution will require a heating and agitation for several hours.

\section{Methods}

There is a wide range of rheological measurement techniques are available and each one has its advantages and disadvantages. To maximize the value of the data generated it is obviously important to ensure that the most appropriate technique is used for the application. The shear viscosity of the prepared solution as a function of shear rate and concentration were measured using Anton Paar's Modular Compact Rheometer (series 102) with cone shaped measuring geometry at $50^{\circ} \mathrm{C}$. The shear viscosity at all solution concentrations, over a shear rate range of 0 to $500 \mathrm{~s}^{-}$ ${ }^{1}$ was measured. The oscillatory frequency test was also carried

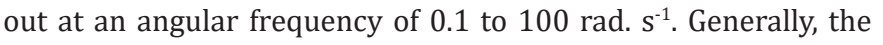

oscillatory tests were carried out to determine the viscoelastic behavior of the solution.

Core flooding experiment were performed to measure the recovery of crude oil by using sand pack system. The crude oil was obtained from Rajasthan oil field, India with API of 19.2 at $28{ }^{\circ} \mathrm{C}$. The sandstone with the permeability of 2.5 milli Darcy and porosity 0.19 was used for the test. During the test, the sand pack was flooded with crude oil at $30 \mathrm{psig}$. Then, the polymer-surfactant and polymer-surfactant-nanoparticle solution was introduced in a sand pack when water cut exceeded $95 \%$.

\section{Results and Discussion}

\section{Effect of different concentration of nanoparticles on viscosity}

Therheological properties of the injected fluid are an important parameter in a chemical flooding process. The additional increase in viscosity of injected fluid, the oil displacement efficiency is increased, and more oil recovered from the porous rock. To observe the effect of silica nanoparticles on the viscosity of polymer solution, the viscosity measurement test was performed with 1.0 wt.\% of a polymer solution and also with polymersurfactants system containing different silica concentration at 50 ${ }^{0} \mathrm{C}$. From a Figure 1, the viscosity of polymer solution increases with increase in a concentration of Nano-silica. The ion-dipole interaction is developed between cations and oxygen atoms in the tetrahedral structure of silica. Thus, the attack of cations to 
polymer molecules is reduced to some extent and the increase in viscosity of the solution is observed in the presence of silica nanoparticles. Consequently, the oil recovery increases during chemical flooding test by increasing the silica nanoparticles concentration [4].

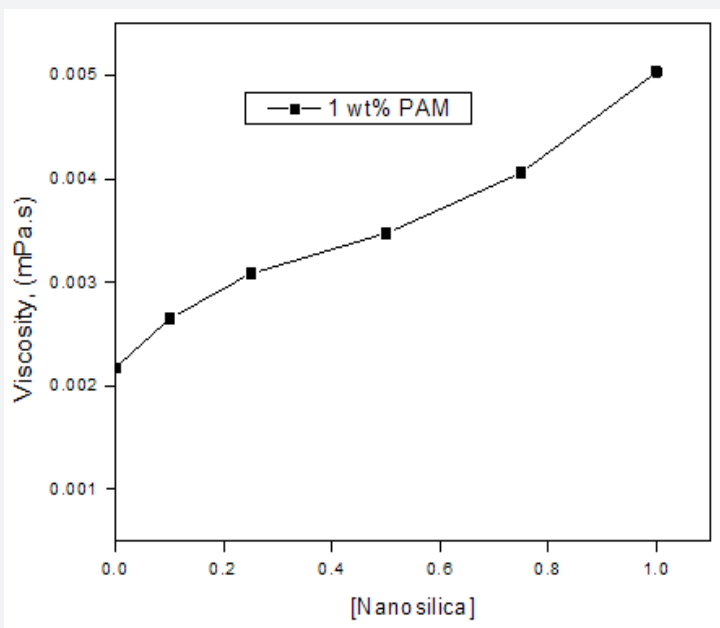

Figure 1: Effect of concentration of Nano-Silica on the viscosity of PAM at $50^{\circ} \mathrm{C}$ and Fix shear rate $\left(\mathrm{Y}=100 \mathrm{~s}^{-1}\right)$.

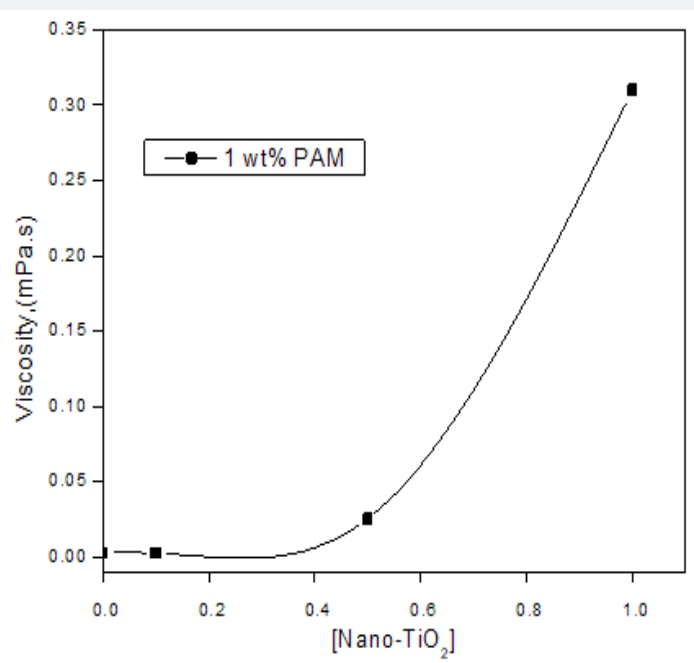

Figure 2: Effect of concentration of $\mathrm{Nano}^{-\mathrm{TiO}_{2}}$ on the viscosity of $\mathrm{PAM}$ at $50^{\circ} \mathrm{C}$ and fix shear rate $\left(\mathrm{Y}=100 \mathrm{~s}^{-1}\right)$.

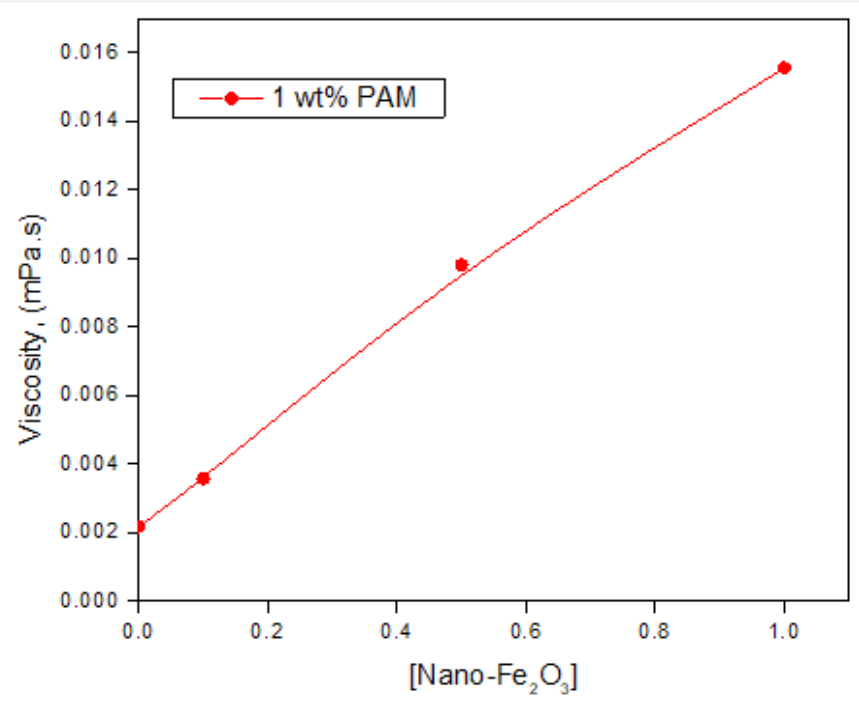

Figure 3: Effect of concentration of Nano- $\mathrm{Fe}_{2} \mathrm{O}_{3}$ on the viscosity of PAM at $50{ }^{\circ} \mathrm{C}$ and Fix shear rate $\left(\mathrm{Y}=100 \mathrm{~s}^{-1}\right)$. 
The same effect of nano- $\mathrm{TiO}_{2}$ and nano- $\mathrm{Fe}_{2} \mathrm{O}_{3}$ on the rheology of polyacrylamide was also obtained at the same operating conditions (Figure 2\&3). The viscosity of the polymer increases with increase in the concentration of nano- $\mathrm{TiO}_{2}$ and nano- $\mathrm{Fe}_{2} \mathrm{O}_{3}$ as expected. But there is a more drastic change in the viscosity of polyacrylamide is observed with the nano- materials of metal oxides. $\mathrm{TiO}_{2}$ shows the ability to provide much better result in enhance oil recovery process while chemical flooding. Comparing with the nano-silica, the nano- $\mathrm{TiO}_{2}$ increases the viscosity of polymer solution up to $83.33 \%$ and the nano- $\mathrm{Fe}_{2} \mathrm{O}_{3}$ increases the viscosity of about $64.28 \%$. Also, some research studies suggested that the reduction of oil viscosity is possible via nanoparticles of metals oxide. A Bayat et al., [11] reported in his work, that $\mathrm{SiO}_{2}$, $\mathrm{TiO}_{2}, \mathrm{Al}_{2} \mathrm{O}_{3}$ and nano-fluids flooding at $60^{\circ} \mathrm{C}$ caused 8,24 and $34 \%$ viscosity reduction compared to the original oil viscosity at the same temperature, respectively. This is because $\mathrm{TiO}_{2}, \mathrm{Al}_{2} \mathrm{O}_{3}$ and $\mathrm{Fe}_{2} \mathrm{O}_{3}$ have higher thermal conductivity than $\mathrm{SiO}_{2}$.

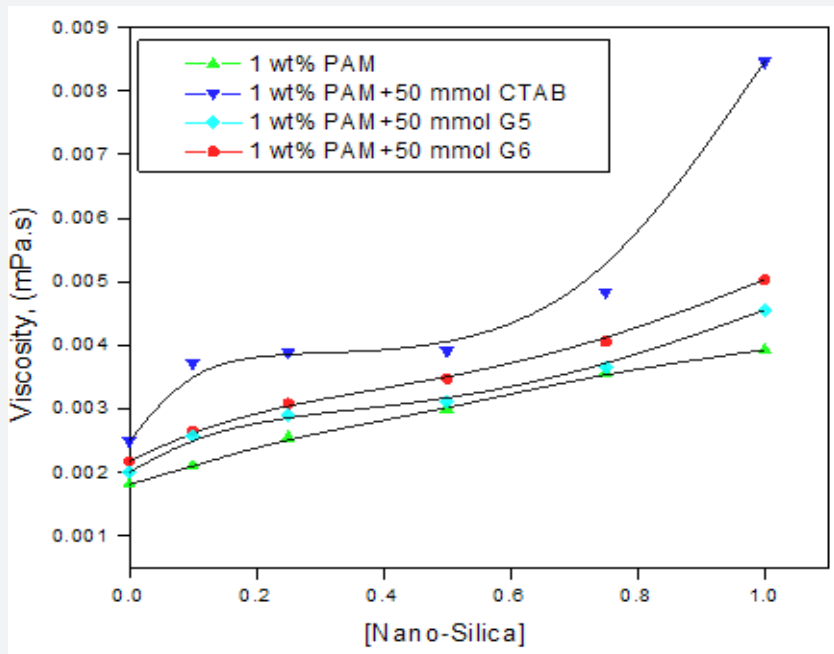

Figure 4: Effect of concentration of Nano-Silica on the viscosity of mixed assembly of polymer and surfactants at $50 \mathrm{OC}$ and Fix shear rate $\left(y=100 \mathrm{~s}^{-1}\right)$.

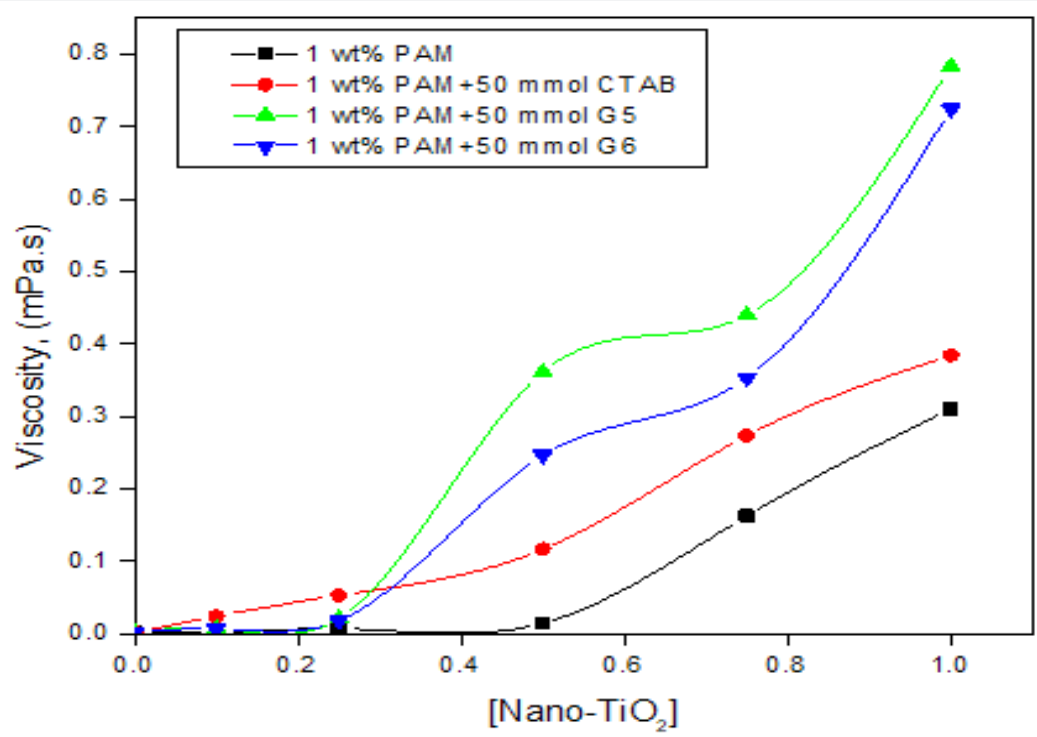

Figure 5: Effect of concentration of $\mathrm{NanO}_{-} \mathrm{TiO}_{2}$ on the viscosity of mixed assembly of polymer and surfactants at $50 \mathrm{OC}$ and Fix shear rate $\left(\gamma=100 \mathrm{~s}^{-1}\right)$.

The effect of nanoparticles on the mixed assembly of polymer and surfactant are shown in Figure 4,5 and 6. The concentration of polymer and surfactants are fixed and the test was conducted at $50{ }^{\circ} \mathrm{C}$. The shear viscosity of all the systems increases with nanosilica concentration. As shown in Figure 4, the polymer solution with CTAB surfactant shows a more drastic change in the viscosity with a given Nano-silica concentration range. In a case of $\mathrm{TiO}_{2}$ and
$\mathrm{Fe}_{2} \mathrm{O}_{3}$, the Gemini (16-5-16) surfactant shows more effect on the rheological property of polyacrylamide. The interaction between the polymer and nanoparticles are affected by the presence of a surfactant (Figure 5\&6). The surfactants in the solution can dislocate and relocate on the surface of the nanomaterial and ultimately created new surfactant coated particles. This will lead to increase in the viscosity of the solution. 


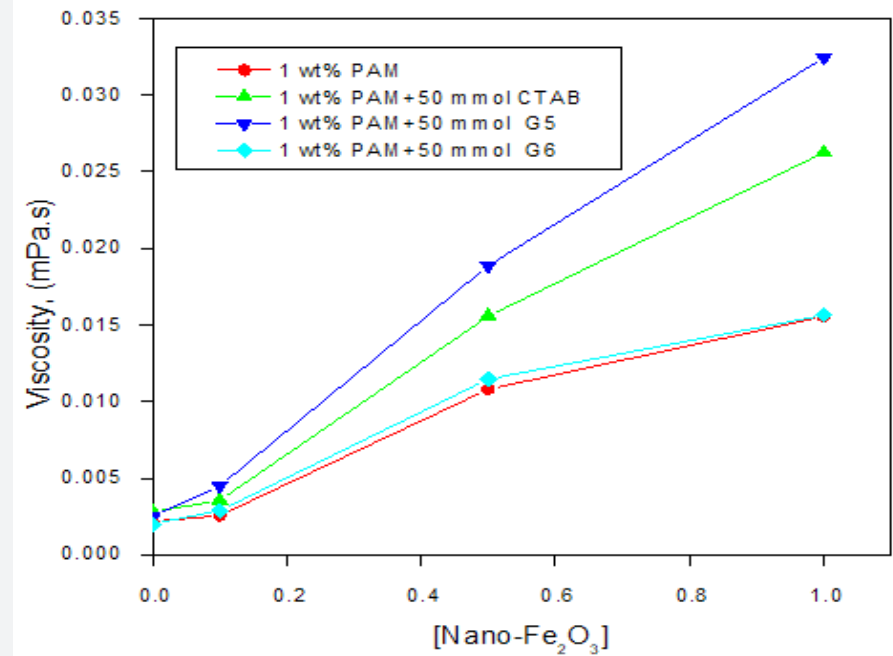

Figure 6: Effect of concentration of $\mathrm{Nano}-\mathrm{Fe}_{2} \mathrm{O}_{3}$ on the viscosity of mixed assembly of polymer and surfactants at $500 \mathrm{C}$ and Fix shear rate $\left(y=100 \mathrm{~s}^{-1}\right)$.

Effect of shear on the rheological properties of the polymer-nanoparticles and polymer-surfactant-nanoparticles hybrid system

In this section, the effects of shear rate on the viscosity of polymer-nanoparticles and polymer-surfactant-nanoparticles hybrid system were studied. The results are plotted in Figure 7, 8 and 9 for a fixed PAM concentration of $0.5 \mathrm{wt} . \%$ with varying concentration of nano-Si, nano- $-\mathrm{TiO}_{2}$ and nano- $\mathrm{Fe}_{2} \mathrm{O}_{3}$ from 0.5 to $1.0 \mathrm{wt} . \%$. The results indicate that the addition of nanoparticles in the polyacrylamide solution leads to increase in viscosity. Because of the irreversible adsorption of polyacrylamide on nanoparticles, the resultant macro-molecular structure is stable and not easily broken, and it leads to increase in viscosity of the system. The viscosity of polymer-nanomaterial system is greater than the viscosity of polyacrylamide solution at same temperature and shear rate. Figure 10, 11 and 12 shows the viscosity variation of polymer-surfactant-nanoparticles hybrid system. Across all the polymer, surfactants and nanoparticles concentrations, it is found that the samples revealed non-Newtonian shear thinning behavior at low shear rate $\left(\gamma<25 \mathrm{~s}^{-1}\right)$. But at high shear rate the solution loses it's non-Newtonian and shows shear thickening behavior [12]. At low shear rate, the viscosity of the system is obviously dropped. The bond between the polymer and nanoparticles are not easily broken in normal state, but progressively weakens as shear rate increases, thus the flow of the suspension is shear thinning [13]. The shear thinning behavior and incremental shear viscosity with concentration of polyacrylamide and nanoparticles can be responsible for strong interaction between polymer and nanoparticles.

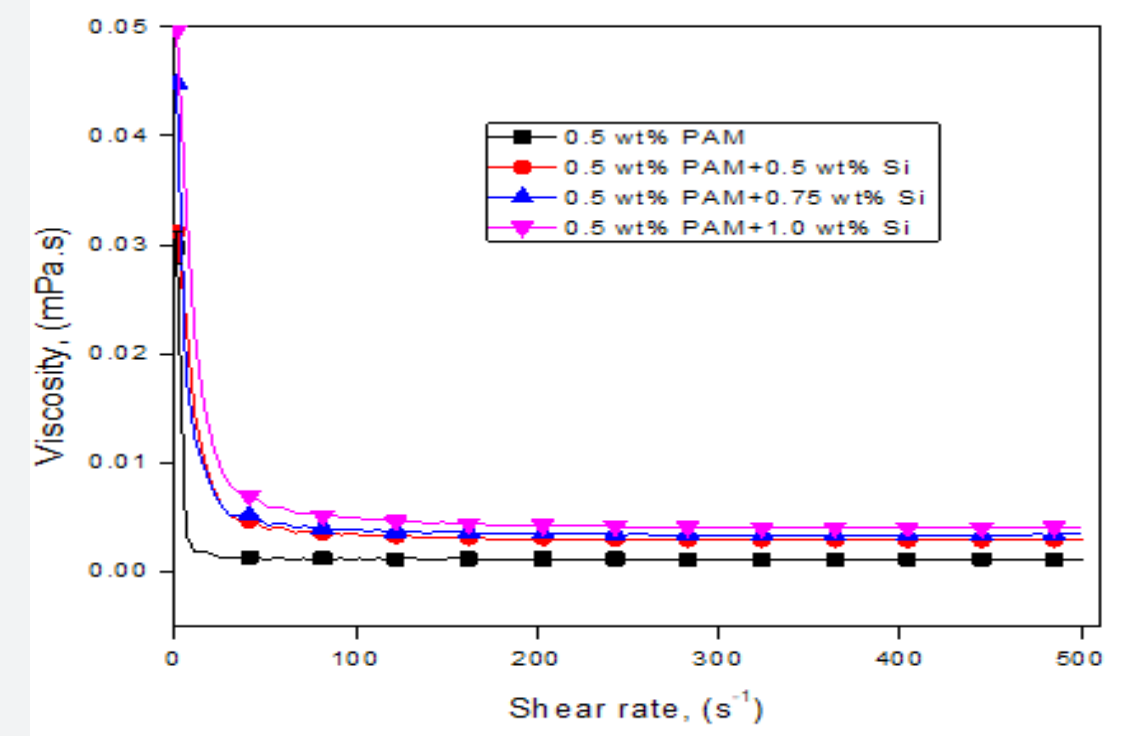

Figure 7: Effect of nano-Si on the Viscosity of polyacrylamide as a function of shear rate $\left(\gamma=0\right.$ to $\left.500 \mathrm{~s}_{-1}\right)$ at $50{ }^{\circ} \mathrm{C}$. 




Figure 8: Effect of nano- $\mathrm{TiO}_{2}$ on the Viscosity of polyacrylamide as a function of shear rate $\left(\mathrm{Y}=0\right.$ to $\left.500 \mathrm{~s}^{-1}\right)$ at $50^{\circ} \mathrm{C}$.

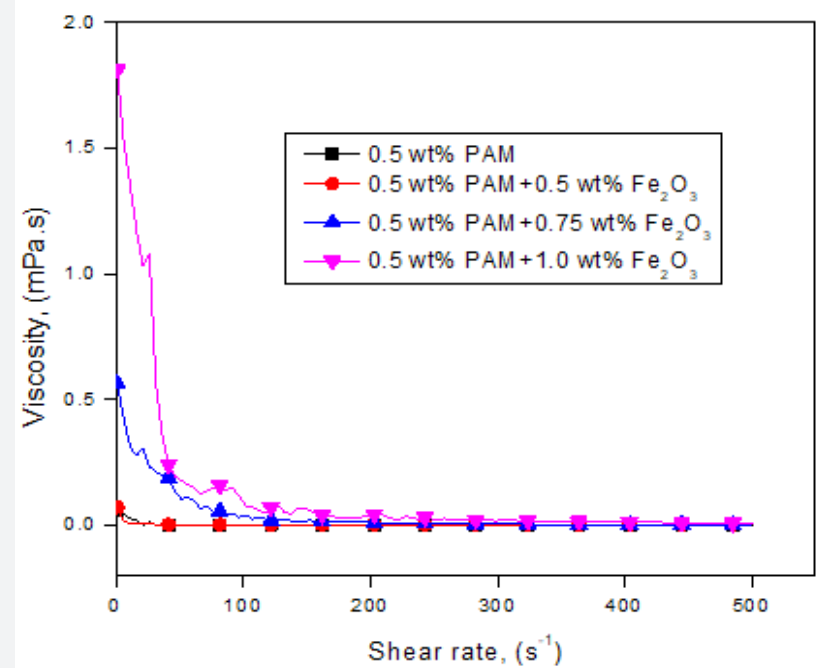

Figure 9: Effect of nano- $\mathrm{Fe}_{2} \mathrm{O}_{3}$ on the Viscosity of polyacrylamide as a function of shear rate $\left(\mathrm{Y}=0\right.$ to $\left.500 \mathrm{~s}^{-1}\right)$ at $50^{\circ} \mathrm{C}$.

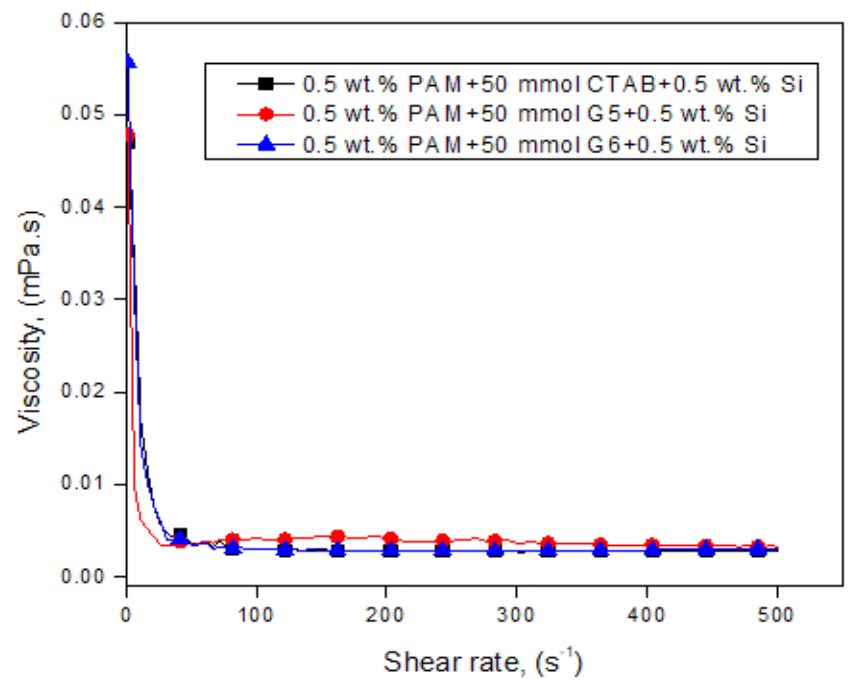

Figure 10: Effect of nano-Si on the Viscosity of polymer-surfactant system as a function of shear rate $\left(Y=0\right.$ to $\left.500 \mathrm{~s}^{-1}\right)$ at $50{ }^{\circ} \mathrm{C}$. 


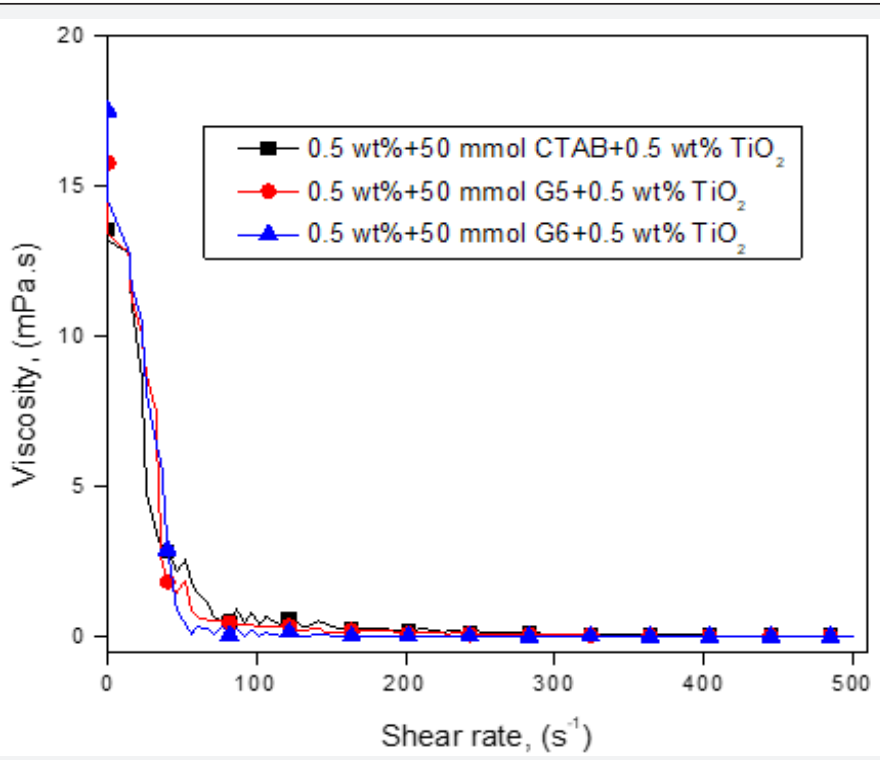

Figure 11: Effect of nano- $\mathrm{TiO}_{2}$ on the Viscosity of polymer-surfactant system as a function of shear rate $\left(\mathrm{Y}=0\right.$ to $\left.500 \mathrm{~s}^{-1}\right)$ at $50{ }^{\circ} \mathrm{C}$.

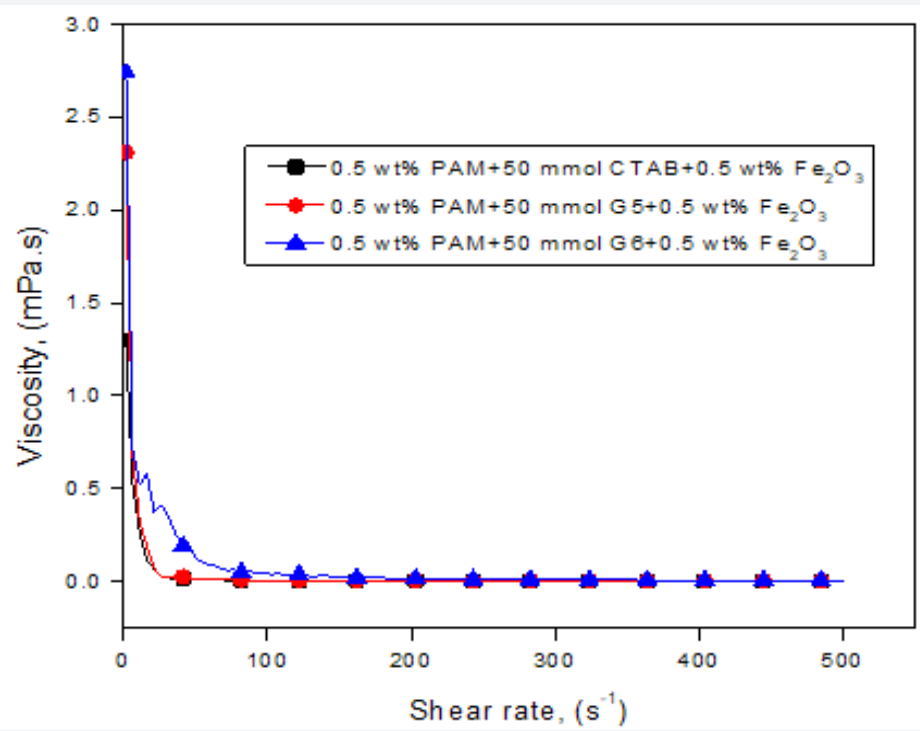

Figure 12: Effect of nano- $\mathrm{Fe}_{2} \mathrm{O}_{3}$ on the Viscosity of polymer-surfactant system as a function of shear rate $\left(\mathrm{Y}=0\right.$ to $\left.500 \mathrm{~s}^{-1}\right)$ at $50{ }^{\circ} \mathrm{C}$.

On the basis of results, adding a small amount of nanoparticles can improve the pseudo-plasticity behavior of polymer solution at a given shear rate. From the above discussion, it is observed that the nano-suspension increases the viscosity of the solution in comparison to polymer viscosity. It indicates that the nanoparticles can increase the sweep efficiency of the polymer solution and oil recovery will be higher with nanoparticles. The more nanoparticles transportation will be the more effective the wettability alteration and better effective sweep efficiency of the polymer-surfactant solution.

\section{Effect of nanoparticles on viscoelastic behavior of poly- mer}

The viscoelastic properties of polymer solution are widely used to gain insight into structure strength of polymer in the solution. The viscoelastic property of polymer plays an important role in increasing the oil recovery. Larger the viscoelasticity, greater will be the sweep efficiency of the polymer solution. Figure 13 shows the plots of storage modulus ( $\left.G^{\prime}\right)$ as a function of oscillatory angular frequency $(\omega)$ for polyacrylamide solution and polymer-silica mixed system at $50{ }^{\circ} \mathrm{C}$. For all the solutions, storage modulus $\mathrm{G}^{\prime}$ is a strong function of angular frequency and increases over the entire range. The elastic part of the polymer is called the storage modulus ( $\left.\mathrm{G}^{\prime}\right)$ and it is a measure of the energy stored and recovered. The viscous part is called the loss modulus G" which is a measure of the energy dissipated [14]. The value of storage modulus increases with increases the concentration of nanoparticles due to the more numbers of nanoparticles available in the solution. With the addition of silica nanoparticles, storage modulus of polymer-silica system greater than that of the polyacrylamide solution. This indicates that the polyacrylamidenanosilica mixed system undergoes microstructural changes 
and they have ability to increase the oil recovery. In the polymersilica mixed system, the interaction between the amide group of polyacrylamide and silanol functional group of nano-silica occurred. So, the structure of polyacrylamide strengthened, and the elasticity of the mixed system becomes more pronounced.
The elastic property is more dominant than the viscous i.e., $G^{\prime}$ is greater than $G^{\prime \prime}$. This indicates that there is a significant buildup of network structure that is responsible for imparting a significant elasticity to the polymer solutions [12].

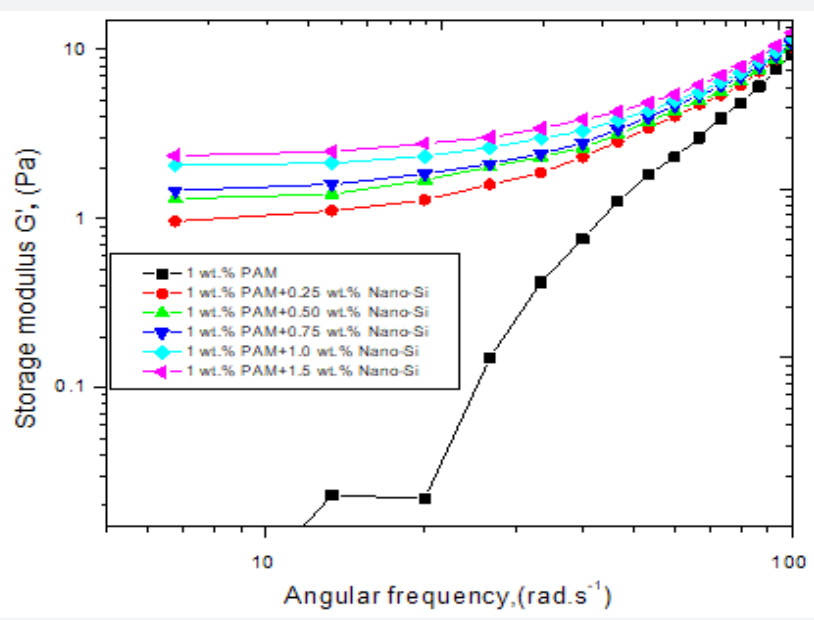

Figure 13: Storage modulus (G') as a function of angular frequency $(\omega)$ for polyacrylamide-Nano-Silica mixed system at $50^{\circ} \mathrm{C}$.

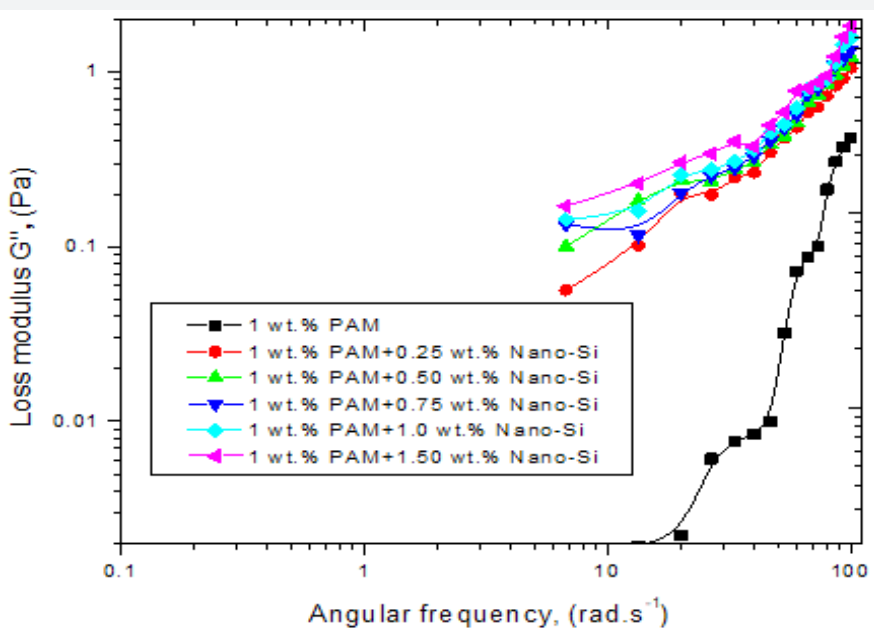

Figure 14: Loss modulus (G") as a function of angular frequency $(\omega)$ for polyacrylamide-Nano-Silica mixed system at $50^{\circ} \mathrm{C}$.

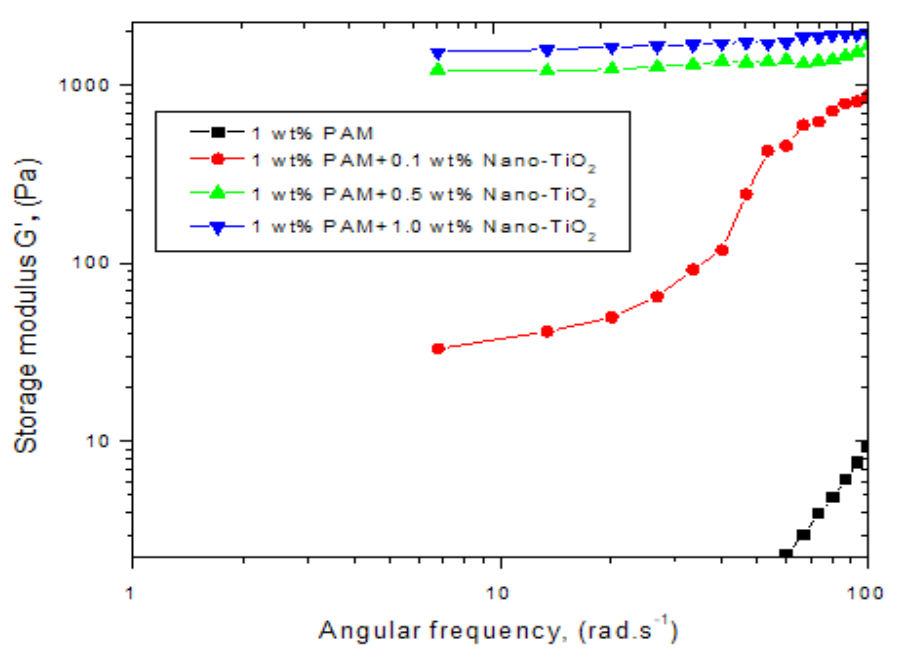

Figure 15: Storage modulus (G') as a function of angular frequency $(\omega)$ for polyacrylamide-Nano- $\mathrm{TiO}_{2}$ mixed system at $50^{\circ} \mathrm{C}$. 
Figure 14 shows the loss modulus (G") as a function of increasing angular frequency for PAM and PAM-silica mixed system. The loss modulus (G") is the characteristic of the viscous behaviors of the solution. When the value of storage modulus is greater than the loss modulus, it represents the solution exhibits viscoelastic gel like behavior and when the value of loss modulus is greater than storage modulus, the system displays a liquid like behavior. The value of G' and G' increased with the angular frequency. On comparing the viscoelastic effect of nano-silica on polymer solution with $\mathrm{TiO}_{2}$ and $\mathrm{Fe}_{2} \mathrm{O}_{3}$ from Figure (15\&17), the storage modulus $\left(G^{\prime}\right)$ of $\mathrm{TiO}_{2}$ is much larger than that of nano-Si and $\mathrm{Fe}_{2} \mathrm{O}_{3}$. G' and $\mathrm{G}^{\prime \prime}$ increases with increase in a concentration of nanoparticles. The increase in a concentration of nanoparticles found to strengthen the network structure of polyacrylamide solution and this leads to increase the viscoelastic properties. At $1.0 \mathrm{wt} . \%$ of $\mathrm{TiO}_{2}$, the flow curve is constant with the increase of angular frequency and $G^{\prime}>G^{\prime \prime}$, this means the elastic effect is more dominant. The elastic behavior of all the above systems is more than that of loss modulus because the decreased friction at the polymer-nanoparticles interface led to the slight decrease in the loss modulus. From (Figure $16 \& 18$ ), the loss modulus is also increasing with the addition of nanoparticles, but the value of loss modulus is slightly less than the storage modulus at all concentration. Also, the value of loss modulus never exceeds to zero [15].

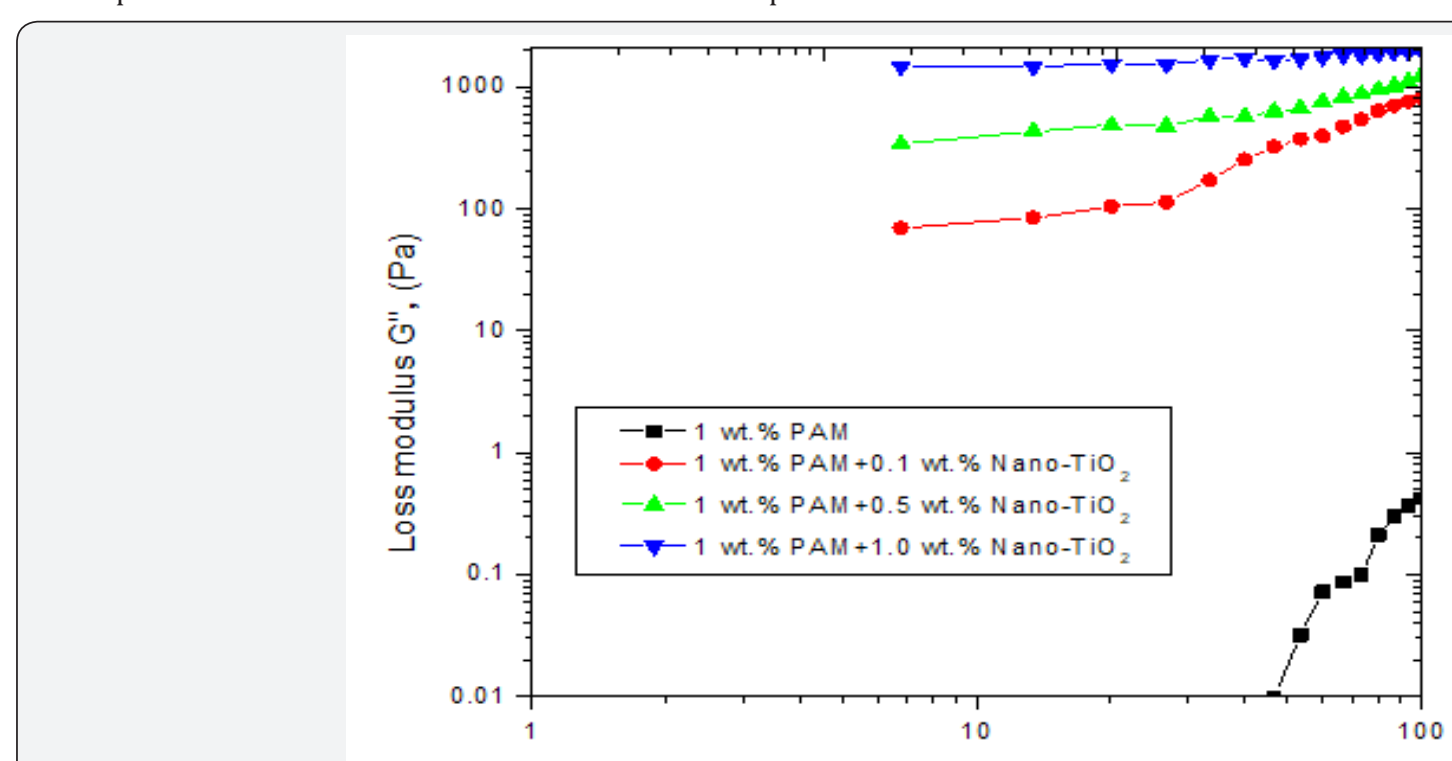

Angular frequency, $\left(\operatorname{rad} . \mathrm{s}^{-1}\right)$

Figure 16: Loss modulus (G") as a function of angular frequency $(\omega)$ for polyacrylamide-Nano- $\mathrm{TiO}_{2}$ mixed system at $50{ }^{\circ} \mathrm{C}$.

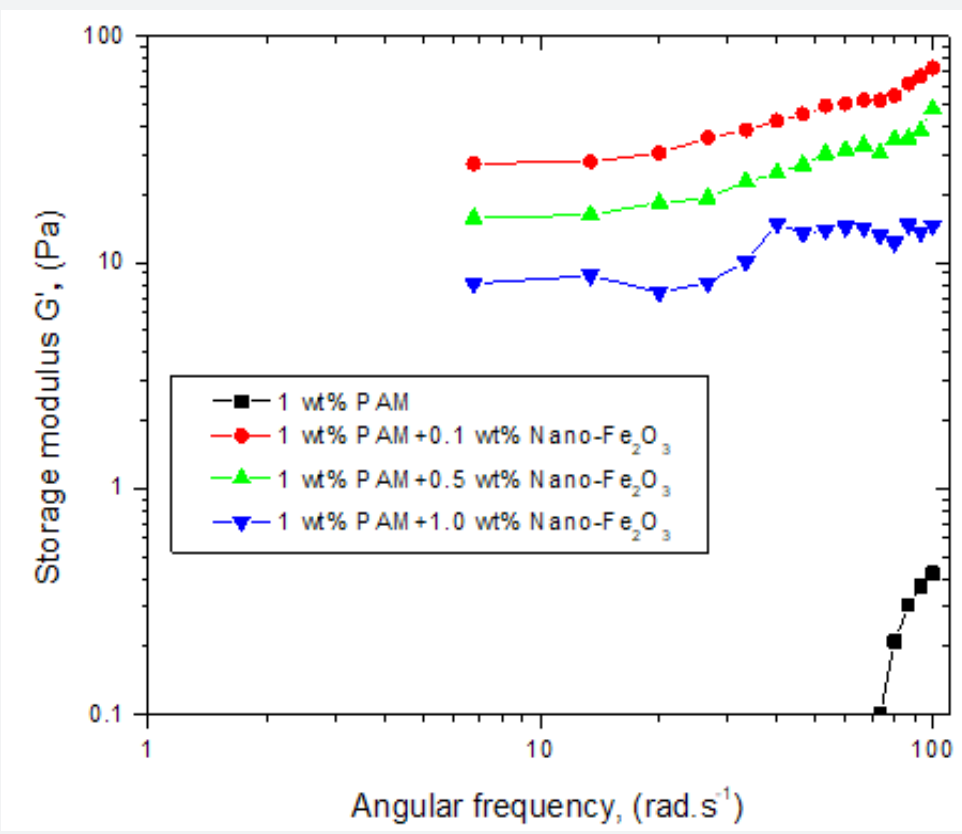

Figure 17: Storage modulus (G') as a function of angular frequency $(\omega)$ for polyacrylamide-Nano- $\mathrm{Fe}_{2} \mathrm{O}_{3}$ mixed system at $50{ }^{\circ} \mathrm{C}$. 


\section{Academic Journal of Polymer science}

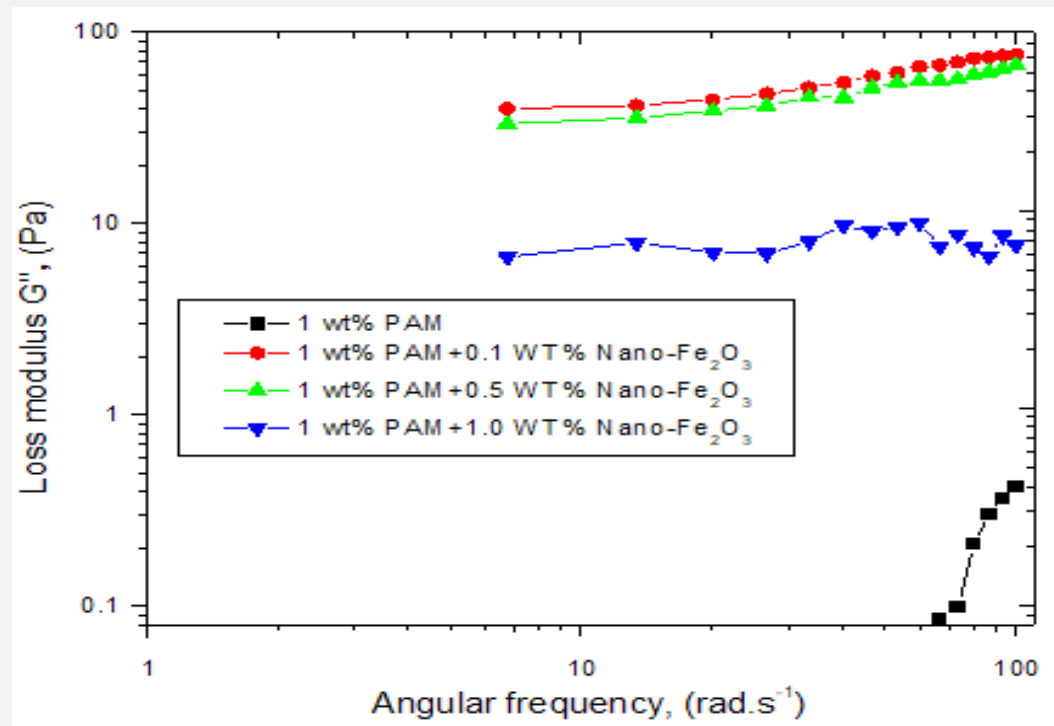

Figure 18: Loss modulus (G") as a function of angular frequency $(\omega)$ for polyacrylamide-Nano- $\mathrm{Fe}_{2} \mathrm{O}_{3}$ mixed system at $50{ }^{\circ} \mathrm{C}$.

\section{Core flooding Results}

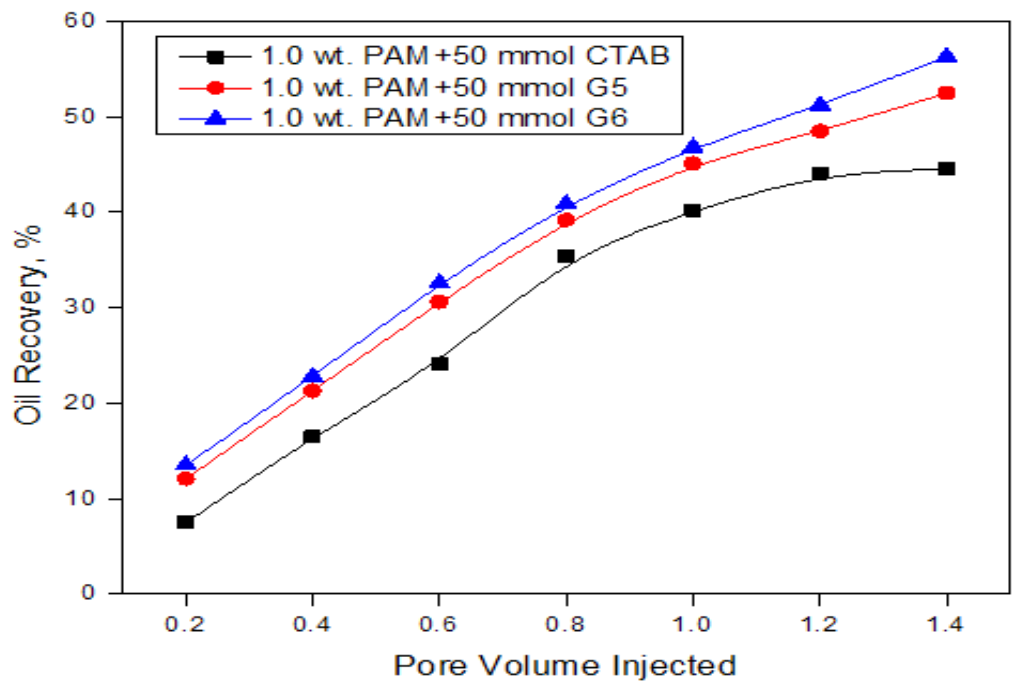

Figure 19: Flooding performance of polymer-surfactant system in sand pack system.



Figure 20: Flooding performance of polymer-nanoparticles system in sand pack system. 
From Figure 19, the core flooding test was conducted by injecting a polymer and surfactant solution. First, the sandstone system saturated with the crude oil and then brine solution is injected to measure the porosity. The porosity of the sandstone system was found 0.19 or $19 \%$. Then the crude oil was flooded with 30psi pressure. Brine solution is then injected in a sand pack system to displace the oil via secondary recovery and around 39\% of oil is recovered. After that the polymer and surfactant solution were injected to recover the remaining oil as tertiary recovery. Additional recovery of $5.5 \%, 13.5 \%$, and $17.3 \%$ were obtained for 1.0 wt. PAM $+50 \mathrm{mmol} \mathrm{CTAB}, 1.0 \mathrm{wt}$. PAM $+50 \mathrm{mmol}$ G5 and $1.0 \mathrm{wt}$. PAM+50 mmol G6 respectively. The polyacrylamide renders the mobility to the oil rich phase by increasing the viscosity of injected fluid. The crude oil droplets are mobilized by reducing the interfacial tension between the oil-water interfaces. As the spaces length of Gemini surfactant increases from 16-5-16 to 16-6-16, the crude oil saturation increases due to improved coalescing of mobilized crude oil droplets to form an oil bank and this result in better oil displacement and hence greater oil recovery. In presence of nanoparticles, the oil recovery percentage is improved as shown in Figure 20. The nanoparticles increase the viscosity of polymer solution significantly and this will lead to increase in storage modulus and loss modulus of polyacrylamide solution, results in the oil recovery will increase. The nano titanium oxide shows good result as compare to nano silica and nano iron oxide material.

\section{Conclusion}

In the present study, the rheological behavior of polyacrylamide and polymer-surfactant solution in the presence of nanoparticles was examined. The result reveals that the presence of nanoparticles strongly influences the rheological properties of solutions. It is found that the shear viscosity of polyacrylamide solution increased with the addition of nanoparticles. With the introduction of nanoparticles in the polymer solution, the polymer chains adsorb on the nanoparticles surface and complex micelle type structure is formed and this interaction leads to increase the viscosity, which indicates that increase in sweep efficiency. A nonNewtonian shear thinning behavior was observed at low shear rate $\left(\gamma<25 \mathrm{~s}^{-1}\right)$. The titanium oxide shows the promising prospects for potential application in enhance oil recovery. The addition of nanoparticles improves the viscoelastic properties of polymer. The additional $11.5 \%, 17.5 \%$ and $22 \%$ of oil recovery were observed in presence of nanoparticles. It means nano-suspension can be used in enhance oil recovery and more beneficial than chemical flooding without nanoparticles.

\section{References}

1. Zhang Y, Chen Y, Westerhoff P, Crittenden J (2009) Impact of natural organic matter and divalent cations on the stability of aqueous nanoparticles. Water Res 43(17): 4249-4257.

2. Skauge T, Spildo K, Skauge A (2010) Nano-sized Particles For EOR. In SPE Improved Oil Recov. Symp. Soc Petrol Eng: Tulsa, USA, p. 10.

3. Chen H, Ding Y, He Y, Tan C (2007) Rheological behaviour of ethylene glycol based titania nanofluids. Chem Phys Letters 444(4-6): 333-337.

4. Maghzi A, Kharrat R, Mohebbi A, Ghazanfari MH (2014) The impact of silica nanoparticles on the performance of polymer solution in presence of salts in polymer flooding for heavy oil recovery. Feul 123 123-132.

5. Roustaei A, Saffarzadeh S, Mohammadi M (2013) An evaluation of modified silica nanoparticles' efficiency in enhancing oil recovery of light and intermediate oil reservoirs. Egyptian Journal of Petroleum. 22(3): 427-433.

6. Maghzi A, Mohebbi A, Kharrat R, Ghazanfari (2013) An experimental investigation of silica nanoparticles effect on the rheological behavior oh polyacrylamide solution to enhance oil recovery. Petroleum Science and Technology 31(5): 500-508.

7. Hu Z, Azmi SM, Raza G, Glover PWJ, Wen D (2016) Nanoparticleassisted water-flooding in Berea sandstones. Energy \& fuels 30(4): 2791-2804

8. Joonaki E, Ghanaatian S (2014) The Application of Nano-fluids for Enhanced Oil Recovery: Effects on Interfacial Tension and Coreflooding Process. Petroleum Science and Technology 32(21): 2599-2607.

9. Pei H, Zhang G, Ge J, Zhang J, Zhang Q (2015) Investigation of Synergy between Nanoparticle and Surfactant in Stabilizing Oil-in-Water Emulsions for Improved Heavy Oil Recovery. Colloids and Surfaces A: Physicochem. Eng Aspects 484: 478-484.

10. Yousefvand H, Jafari A (2015) Enhance oil recovery using Polymer/ nanosilica. Procedia Material Science 11: 565-570.

11. Bayat AE, Junin R, Samsuri A, Piroozian A, Hokmabadi M (2014) Impact of Metal Oxide Nanoparticles on Enhanced Oil Recovery from Limestone Media at Several Temperatures. Energy \& fuels 28(10): $6255-6266$

12. Khan MB (2017) Rheological behavior of polyacrylamide solution in the presence of cationic Gemini surfactants/conventional surfactants. Asia-Pac J Chem Eng 12(4): 671-678.

13. Kamibayashi M, Ogura H, Otsubo Y (2005) Viscosity behavior of silica suspensions flocculated by associating polymers. J Colloid Interface Sci 290(2): 592-597.

14. Khan MB, Khan MS (2018) Investigating the Influence of Alkali, Salts on Rheological Properties of Polyacrylamide and Mixed Assembly of Polymer-Surfactant. Chem Data Collection 13-14: 60-72.

15. Aalaie J (2016) Viscoelastic Properties of Polyacrylamide Nanocomposite Hydrogels Prepared in Electrolyte Media: Effect of Gelant Volume. Journal of Petroleum Science and Technology 6(1): 8087. 
This work is licensed under Creative Commons Attribution 4.0 License

DOI: 10.19080/AJOP.2018.01.555573
Your next submission with Juniper Publishers will reach you the below assets

- Quality Editorial service

- Swift Peer Review

- Reprints availability

- E-prints Service

- Manuscript Podcast for convenient understanding

- Global attainment for your research

- Manuscript accessibility in different formats ( Pdf, E-pub, Full Text, Audio)

- Unceasing customer service

Track the below URL for one-step submission https://juniperpublishers.com/online-submission.php 